\title{
Acute and chronic metabolic acidosis interferes with aquaporin-2 translocation in the rat kidney collecting ducts
}

\author{
Tomohiko Mouri $^{1}$, Takeaki Inoue ${ }^{1}$, Hiroshi Nonoguchi ${ }^{2}$, Yushi Nakayama ${ }^{1}$, Hiroki Miyazaki ${ }^{1}$, \\ Takanobu Matsuzaki ${ }^{3}$, Hideyuki Saito ${ }^{3}$, Takeshi Nakanishi ${ }^{2}$, Yukimasa Kohda ${ }^{1}$ and Kimio Tomita ${ }^{1}$
}

Renal aquaporin-2 (AQP2) expression plays a key role in urine concentration. However, it is not known whether metabolic acidosis affects urine-concentrating ability through AQP2 expression in the kidney and urine. We examined urinary excretion and renal expression of AQP2 in control and acidosis rats, using RT-competitive PCR, immunoblot and immunocytochemistry. Urinary excretion of AQP2 is decreased by 92\% even with the increase in AQP2 mRNA and protein expressions in the collecting ducts by metabolic acidosis in rats. Urine osmolality in control rats was $1670 \pm 198 \mathrm{mOsm}$ per $\mathrm{kg} \mathrm{H}_{2} \mathrm{O}$, and immunocytochemistry revealed the presence of AQP2 in the apical plasma membrane of the principal cells in the collecting ducts. Urine osmolality in acidosis rats was lower than that in control $\left(1397 \pm 243 \mathrm{mOsm}\right.$ per $\mathrm{kg} \mathrm{H} \mathrm{H}_{2} \mathrm{O}$ ), and immunocytochemistry showed the diffuse presence of AQP2 in the cytoplasm of the principal cells. Differential centrifugationcoupled immunoblot showed a significant decrease in the ratio of AQP2 in plasma membrane-enriched fraction to that in intracellular vesicle-enriched fraction by metabolic acidosis. In summary, AQP2 translocation is largely decreased by metabolic acidosis even with increased expression in the collecting ducts. A disorder of AQP2 translocation in the collecting ducts with acidosis may be responsible for the diuresis in patients with chronic renal failure.

Hypertension Research (2009) 32, 358-363; doi:10.1038/hr.2009.19; published online 20 March 2009

Keywords: aquaporin-2; metabolic acidosis; principal cell; trafficking; vasopressin

\section{INTRODUCTION}

Urine concentration plays a key role in the maintenance of body fluid homeostasis by the kidney. Patients with chronic renal failure possess a defect in urine-concentrating ability, which is mainly because of diminished interstitial osmotic gradient and decreased aquaporins (AQPs) expression, including AQP2 in the collecting ducts. ${ }^{1}$ Vasopressin increases osmotic water permeability in the collecting ducts and plays a key role in urine concentration. ${ }^{2-4} \mathrm{AQP} 2$ is a vasopressinsensitive water channel, which is present in the apical plasma membrane of the principal cells of the collecting ducts. ${ }^{5-7}$ AQP3 and AQP4 are present in the basolateral membrane of the same cell but are insensitive to vasopressin. Among them, AQP2 plays a key role in water reabsorption in the distal nephron. AQP2 is excreted into the urine and the excretion is proportional to urine osmolality. ${ }^{8}$ Vasopressin stimulates the accumulation of AQP2 in the apical plasma membrane of the principal cell by trafficking from intracellular vesicles. ${ }^{9,10}$

Metabolic acidosis is developed in patients with chronic renal failure, and we have reported that metabolic acidosis affected V1a and V2 receptor expression in collecting ducts. ${ }^{11}$ However, it is not known whether metabolic acidosis affects AQP2 expression in the kidney. Recently, Amlal et al. ${ }^{12}$ reported that metabolic acidosis increased AQP2 expression in the collecting ducts by the activation of plasma vasopressin level. They used a $0.28 \mathrm{M} \mathrm{NH}_{4} \mathrm{Cl}$ solution for the induction of metabolic acidosis. However, the $0.28 \mathrm{M} \mathrm{NH} \mathrm{NH}_{4} \mathrm{Cl}$ solution is hypertonic $\left(560 \mathrm{mOsm}\right.$ per $\mathrm{kg} \mathrm{H}_{2} \mathrm{O}$ ). The intake of the hypertonic solution caused the increase in plasma osmolality and subsequent increase in the secretion of vasopressin; the stimulated vasopressin might have increased AQP2 expression in the collecting ducts in their study. ${ }^{13}$ The addition of $\mathrm{NH}_{4} \mathrm{Cl}$ to food has been recently used for the induction of metabolic acidosis to avoid the occurrence of dehydration. $^{14,15}$ This model is better, as the plasma level of vasopressin is not different from that in control rats.

To know whether the AQP2 protein expression in the kidney is affected by chronic metabolic acidosis, we examined AQP2 mRNA and protein expressions in the kidney and urine using rats with metabolic acidosis.

${ }^{1}$ Department of Nephrology, Kumamoto University Graduate School of Medical Sciences, Kumamoto, Japan; ${ }^{2}$ Division of Kidney and Dialysis, Department of Internal Medicine, Hyogo College of Medicine, Nishinomiya, Hyogo, Japan and ${ }^{3}$ Department of Pharmacy, Kumamoto University Hospital, Honjo, Kumamoto, Kumamoto, Japan Correspondence: Dr H Nonoguchi, Division of Kidney and Dialysis, Department of Internal Medicine, Hyogo College of Medicine, 1-1 Mukogawa-cho, Nishinomiya, Hyogo 663-8501, Japan.

E-mail: nono@hyo-med.ac.jp

Received 27 August 2008; revised 13 January 2009; accepted 1 February 2009; published online 20 March 2009 


\section{METHODS}

Animals

Four-week-old male Sprague-Dawley rats were used in this study. Metabolic acidosis was induced by the addition of $\mathrm{NH}_{4} \mathrm{Cl}$ in the food for 5-6 days as reported earlier. ${ }^{11,14,15}$ In brief, $0.2 \mathrm{~g} \mathrm{NH}_{4} \mathrm{Cl}$ was added to $8 \mathrm{~g}$ of standard rat chow per $100 \mathrm{~g}$ of body weight per day in the acidosis group. The same amount of food was given every day to both acidosis and control groups. This procedure was proven not to stimulate changes in the plasma levels of vasopressin or in body weight. Plasma and urine osmolality was measured using an osmometer (Fiske, Norwood, MA, USA). The protocol of our study was reviewed and approved by the Experimental Animal Committee of the Kumamoto University Graduate School of Medical Sciences (Nos. 18-059 and 19-063).

\section{Microdissection of nephron segments}

To examine mRNA and protein expression of AQP2, outer medullary collecting ducts (OMCDs) were microdissected from acidosis and control rats as reported earlier. ${ }^{11,15}$ The left kidney was perfused in vivo initially with $10 \mathrm{ml}$ of an icecold dissection solution (solution A (mM): $130 \mathrm{NaCl}, 5 \mathrm{KCl}, 1 \mathrm{Na}_{2} \mathrm{H}_{2} \mathrm{PO}_{4}$, $1 \mathrm{MgSO}_{4}, 1 \mathrm{Ca}$ lactate, $2 \mathrm{Na}$ acetate, 5.5 glucose and 10 Hepes (pH 7.4 by $\mathrm{NaOH})$ ) and then with $10 \mathrm{ml}$ of the same solution A containing $1 \mathrm{mg} \mathrm{ml}^{-1}$ of collagenase and $1 \mathrm{mg} \mathrm{ml}^{-1}$ of bovine serum albumin (solution B). The coronal sections were transferred into tubes containing $3 \mathrm{ml}$ of solution B containing $150 \mu \mathrm{l}$ of vanadyl ribonucleoside complex (VRC), a potent RNase inhibitor. The tubes were incubated for $30 \mathrm{~min}$ at $37^{\circ} \mathrm{C}$ in a shaking water bath. The solutions were bubbled with $100 \%$ oxygen during incubation. The slices were then transferred into a dissection dish that contained $10 \mathrm{~mm}$ of VRC. OMCD of $1-2 \mathrm{~mm}$ for the determination of AQP2 mRNA, and 5-20 mm of OMCD was used for western blotting.

\section{Incubation of OMCD in different bicarbonate solutions}

To investigate the acute effects of metabolic acidosis, OMCDs microdissected from control rats were incubated in 25,21 and $15 \mathrm{mEql}^{-1}$ bicarbonatecontaining buffer for $1.5 \mathrm{~h}$ at $37^{\circ} \mathrm{C}$. The composition of the solution was the same as that in solution A, except that the bicarbonate buffer contained $\mathrm{NaHCO}_{3}$ but not Hepes. ${ }^{11,15} \mathrm{NaCl}$ was reduced according to the content of $\mathrm{NaHCO}_{3}$ to maintain the same osmolality. After incubation, the tube was centrifuged, the supernatant discarded, and OMCD was used for the determination of the AQP2 mRNA expression.

\section{RT-competitive PCR}

To examine the quantitative expression of the AQP2 mRNA expression, RTcompetitive PCR was performed as described earlier. ${ }^{11,15}$ Specific primers for AQP2 were designed. Sense and anti-sense AQP2 primers were defined by bases 232-252 (5'-TGGGCATCGGCATCCTGGTT-3') and by bases 765-784 (5'AGCGCTCCTGCAGGCTCTTT- $3^{\prime}$ ), respectively. ${ }^{6}$ The predicted size of amplified cDNA was $553 \mathrm{bp}$. The DNA competitor was synthesized using in vitro overlap extension PCR as reported earlier. ${ }^{16,17}$ The inner sense and inner antisense primers for AQP2 were defined by bases 545-564 (5'-GTGGGGACCTGG CTGTCAATGTGACAACCTGGGTAGCCCT- $\left.3^{\prime}\right)$ and by bases $422-441$ (5'-AG GGCTACCCAGGTTGTCACATTGACAGCCAGGTCCCCAC- $3^{\prime}$ ), respectively (the complementary sequences added to each $5^{\prime}$-end was underlined). ${ }^{6}$ The size of the DNA competitor for AQP2 was $450 \mathrm{bp}$. The PCR products were ethanol precipitated and electrophoresed in $2 \%$ agarose gel in Tris-acetateEDTA (TAE). The PCR products were visualized using ethidium bromide staining. For quantitative measurements of AQP2 mRNA expressions, the intensity of the bands was measured using a densitometer (Atto, Tokyo, Japan). The TAE buffer was composed (in mM) of 40 Tris and 1 ethylenediaminetetraacetic acid ( $\mathrm{PH} 8.3$ by acetic acid).

\section{Urine collection}

On the last day of the experiment, $24 \mathrm{~h}$ of urine was collected in a chilled lysis buffer as reported earlier with slight modifications. ${ }^{18,19}$ The lysis buffer was changed to the buffer as reported earlier. ${ }^{20}$ Protein concentration in each urine sample was adjusted by urine creatinine concentration.

\section{Western blotting}

To examine the AQP2 protein expression, western blot analysis was performed using urine sample and microdissected OMCD as reported earlier. ${ }^{11,15}$ Urine sample was centrifuged at 7600 r.p.m. for $15 \mathrm{~min}$ at $4{ }^{\circ} \mathrm{C}$. The supernatant was then centrifuged at 20000 r.p.m. for $30 \mathrm{~min}$ at $4{ }^{\circ} \mathrm{C}$. The remaining pellet was used for the determination of AQP2 in the urine. After SDS-PAGE, the protein was transferred onto a nylon membrane, which was incubated overnight at $4{ }^{\circ} \mathrm{C}$ with the primary antibody against AQP2 (a kind gift from Drs MA Knepper and $\mathrm{S}$ Nielsen). The membrane was then incubated with horseradish peroxidase-linked anti-rabbit $\operatorname{IgG~} \mathrm{F}\left(\mathrm{ab}^{\prime}\right)_{2}$ for $1 \mathrm{~h}$ at room temperature. The protein expression was visualized using ECL western blotting detection reagents.

\section{Differential centrifugation}

Differential centrifugation was carried out as described earlier. ${ }^{21-23}$ Kidneys from control and acidosis rats were homogenized in an ice-cold isolation solution (10 mM triethanolamine ( $\mathrm{pH} 7.6)$ and $250 \mathrm{~mm}$ sucrose) containing protease inhibitors, leupeptin $\left(1 \mu \mathrm{g} \mathrm{ml}^{-1}\right.$; Peptide Institute, Osaka, Japan) and phenylmethylsulfonyl fluoride $\left(0.1 \mathrm{mg} \mathrm{ml}^{-1}\right.$; Wako Pure Chemical, Tokyo, Japan), some of which were collected as whole-kidney homogenates. The remainders were centrifuged initially at $4000 \mathrm{~g}$ for $10 \mathrm{~min}$ at $4{ }^{\circ} \mathrm{C}$ (Himac centrifuge CR5B, Hitachi, Tokyo, Japan) to remove incompletely homogenized fragments and nuclei. The supernatants were collected and centrifuged at $17000 \mathrm{~g}$ for $20 \mathrm{~min}$ (Avanti centrifuge HP-25I, Beckman, Palo Alto, CA, USA). The pellets ('high-density membrane fraction') were retained, and the supernatants were then pelleted by centrifugation at $200000 \mathrm{~g}$ for $1 \mathrm{~h}(\mathrm{SCP} 85 \mathrm{H} 2$, Hitachi) ('low-density membrane fraction'). As documented earlier, ${ }^{21-23}$ the low-density membrane fraction from this protocol is virtually devoid of plasma membranes. After the resuspension of pellets in an isolation solution, the protein concentration in each sample was measured spectrophotometrically using the Pierce BCA (bicinchoninic acid) protein assay reagent kit (Thermo Fisher Scientific Inc., Rockford, IL, USA). These samples were solubilized at $90{ }^{\circ} \mathrm{C}$ for $5 \mathrm{~min}$ in a Laemmli sample buffer before immunoblotting.

\section{Immunocytochemistry}

To examine the cellular localization of AQP2, immunocytochemistry was performed as reported earlier. ${ }^{18}$ The kidneys in control and in acidosis rats were perfused with $4 \%$ paraformaldehyde (PFA) in a phosphate-buffered saline (PBS), and the kidney blocks were incubated in the same solution for $2-3 \mathrm{~h}$. The kidney blocks were then dehydrated in $10 \%$ sucrose with a $2 \%$ PFA solution for $2 \mathrm{~h}, 15 \%$ sucrose with a $2 \%$ PFA solution for $2 \mathrm{~h}$ and with $20 \%$ sucrose with a $2 \%$ PFA solution overnight. The blocks were then mounted on an optimal cutting temperature (OCT) compound and quickly frozen in liquid nitrogen. Sections of $4-5 \mu \mathrm{m}$ thickness were cut and mounted on the coated slides. After incubation with goat serum for $1 \mathrm{~h}$, the slides were incubated overnight at $4{ }^{\circ} \mathrm{C}$ with affinity-purified anti-AQP-2 antibody. After rinsing with PBS, the sections were incubated with fluorescein-5-isothiocyanate-conjugated goat-anti-rabbit $\operatorname{IgG} \quad \mathrm{F}(\mathrm{ab})_{2}$ for $1 \mathrm{~h}$ at room temperature. The sections were sealed with $10 \%$ PBS and $90 \%$ glycerol and with $0.3 \%$ para-phenylenediamine. They were photographed using a fluorescent microscope (Olympus BX 50, Olympus, Tokyo, Japan) or a confocal laser-scanning microscope (Fluoview FV500, Olympus)

\section{Statistics}

The results were shown as mean \pm s.e. Student's $t$-test or ANOVA (analysis of variance) with multiple comparisons of Dunnett's test was used. $P<0.05$ was considered statistically significant.

\section{RESULTS}

\section{Characteristics of rats}

After 5-6 days of administering $\mathrm{NH}_{4} \mathrm{Cl}$ to the rats, their body weight was not found to be different from that of control rats (Table 1). No food was left in the cages of used rats. Plasma levels of bicarbonate and $\mathrm{pH}$ in acidosis rats were significantly lower 
Table 1 Characteristics of rats

\begin{tabular}{lcc}
\hline & Control & Acidosis \\
\hline Body weight & $125 \pm 11$ & $121 \pm 14$ \\
Plasma pH & $7.379 \pm 0.252$ & $7.216 \pm 0.364^{*}$ \\
Plasma $\mathrm{HCO}_{3}{ }^{-}$ & $26.4 \pm 2.2$ & $19.5 \pm 2.3^{*}$ \\
Urine volume & $6.2 \pm 2.3$ & $13.5 \pm 6.2^{*}$ \\
Urine osmolality & $1670 \pm 198$ & $1397 \pm 243^{*}$ \\
\hline
\end{tabular}

Acidosis rats showed low plasma $\mathrm{pH}$, bicarbonate and urine osmolality and large urine volume compared with that of control. Body weight $(\mathrm{g})$, plasma $\mathrm{HCO}_{3}{ }^{-}\left(\mathrm{mEql}^{-1}\right)$, urine volume (ml per day) and urine osmolality (mOsm per $\left.\mathrm{kg} \mathrm{H}_{2} \mathrm{O}\right)$. ${ }^{*} P<0.05$ vs. control $(n=6-10)$.
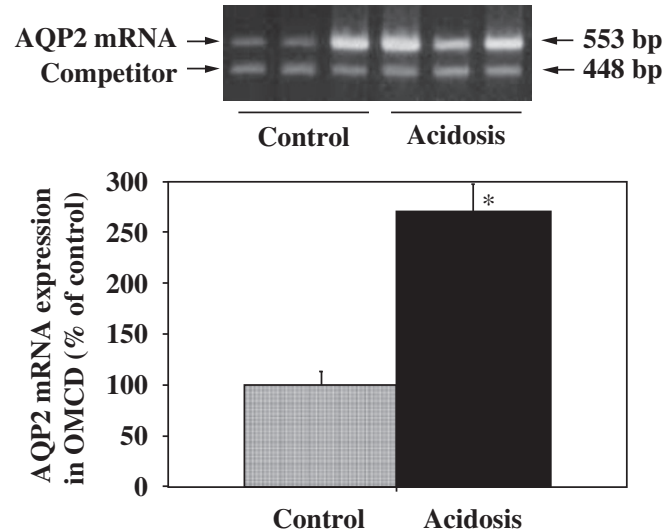

Figure 1 AQP2 mRNA expression in OMCD in control and chronic metabolic acidosis rats. The upper panel shows a typical example of the gel. The upper band represents AQP2 mRNA (553 bp) and the lower band represents the DNA competitor $(448 \mathrm{bp})$. The lower graph shows a mean \pm s.e. of five experiments. Chronic metabolic acidosis significantly increased AQP2 mRNA expression in OMCD by $175 \pm 20 \%$. ${ }^{*} P<0.05$ vs. control. AQP2, aquaporin-2; $\mathrm{OMCD}$, outer medullary collecting duct.

than those in control rats. Urine volume in acidosis rats was significantly larger than in control rats, and urine osmolality in acidosis rats was significantly lower than in control rats.

\section{AQP2 mRNA expression in OMCD in control and chronic} metabolic acidosis rats

Aquaporin-2 mRNA expression in OMCD was clarified using competitive RT-PCR. Chronic metabolic acidosis significantly increased AQP2 mRNA expression in OMCD by $175 \pm 20 \%$ (Figure 1).

\section{AQP2 mRNA expression in OMCD in acute metabolic acidosis} To examine the effects of acute metabolic acidosis on the AQP2 mRNA expression, competitive RT-PCR was performed using OMCD incubated in 17,21 and $25 \mathrm{mEql}^{-1}$ bicarbonate-containing solution for $1.5 \mathrm{~h}$. In OMCD, incubated in 17 and $21 \mathrm{mEq} \mathrm{l}^{-1}$ bicarbonatecontaining solution, the AQP2 mRNA expression was significantly increased by $110 \pm 23$ and $48 \pm 17 \%$, respectively, compared with that in a $25-\mathrm{mEql}^{-1}$ solution (Figure 2).

\section{AQP2 protein in OMCD in metabolic acidosis}

Microdissected OMCD of $5-20 \mathrm{~mm}$ from control and acidosis rats were used for western blot analysis of AQP2. Metabolic acidosis significantly increased AQP2 expression in OMCD by $78 \pm 21 \%$ (Figure 3).
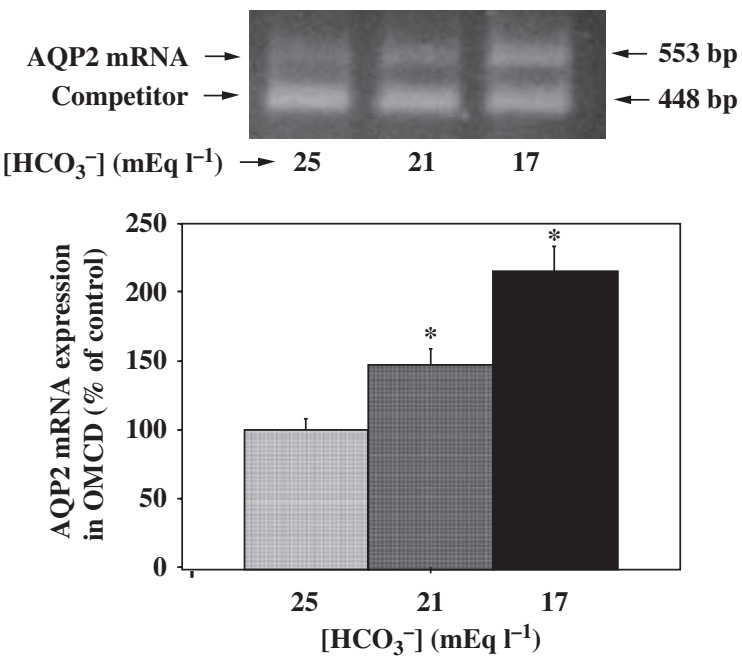

Figure 2 AQP2 mRNA expression in OMCD in acute metabolic acidosis. The upper panel shows a typical example of the gel. The lower graph shows a mean \pm s.e. of four experiments. In OMCD, incubated in 17 and $21 \mathrm{mEqI}^{-1}$ bicarbonate-containing solution, AQP2 mRNA expression was significantly increased by $110 \pm 23$ and $48 \pm 17 \%$, respectively, compared with that in a $25-\mathrm{mEqI}^{-1}$ solution. ${ }^{*} P<0.05$ vs. control (ANOVA (analysis of variance) and multiple comparisons of Dunnett' test). AQP2, aquaporin-2; OMCD, outer medullary collecting duct.

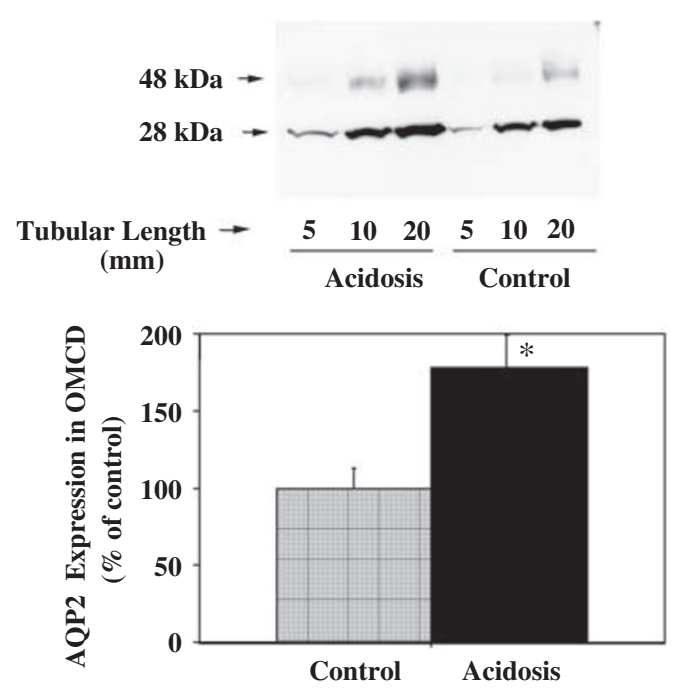

Figure 3 AQP2 protein in OMCD in metabolic acidosis. For western blot analysis, 5-20 mm of microdissected OMCD from control and acidosis rats were used. The upper panel shows a typical example of the western blot. The upper $(48 \mathrm{kDa})$ and lower $(28 \mathrm{kDa})$ bands represent AQP2 protein. The lower graph shows a mean \pm s.e. of four experiments. Metabolic acidosis increased AQP2 expression in OMCD by $78 \pm 21 \%$. ${ }^{*} P<0.05$ vs. control. $A Q P 2$, aquaporin-2; OMCD, outer medullary collecting duct.

AQP2 in urine in control and chronic metabolic acidosis rats Urine was collected for $24 \mathrm{~h}$ on the last day of the experiment. Protein concentration in urine was adjusted using urinary creatinine concentration. Protein in urine was solubilized using a $5 \times$ Laemmli sample buffer. 

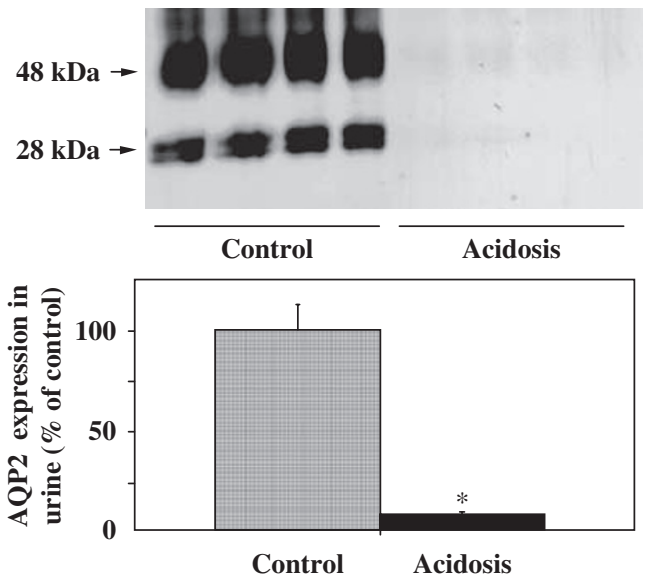

Figure 4 AQP2 in urine in control and chronic metabolic acidosis rats. Protein concentration in urine was adjusted using urinary creatinine concentration. Protein in urine was solubilized by lysis buffer. Chronic metabolic acidosis significantly decreased urinary AQP2 protein by $92 \pm 8 \%$. ${ }^{*} P<0.05$ vs. control. AQP2, aquaporin-2.
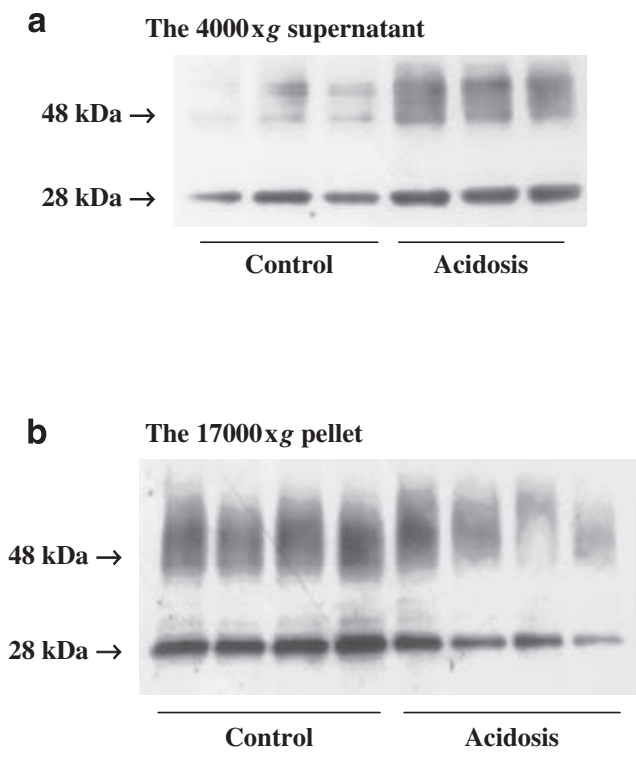

C

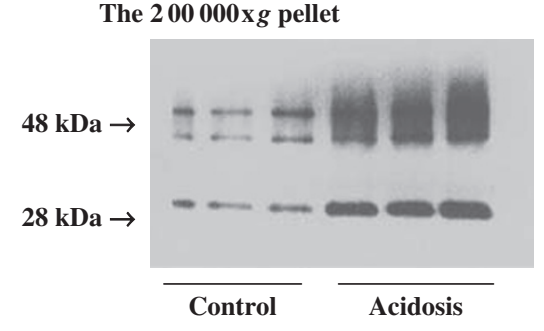

AQP2 was detected in the urine at 28 and $48 \mathrm{kDa}$ as reported earlier. ${ }^{7,16,17}$ Chronic metabolic acidosis significantly decreased urinary AQP2 protein by $92 \pm 8 \%$ (Figure 4 ).

\section{Differential centrifugation}

In spite of a marked decrease in urinary AQP2 in acidosis rats, AQP2 protein in OMCD was increased by acidosis, suggesting that it affects the intracellular localization of AQP2. To understand it, differential centrifugation technique was used, using whole kidney from acidosis and control rats. As shown in Figure 5a, there was a significant increase in AQP2 band density in whole-kidney homogenates from acidosis rats compared with that in control rats, in agreement with the results of immunoblot with microdissected OMCDs (Figure 3). In the highdensity membrane fraction, which contains a predominantly plasma membrane, AQP2 band density was higher in control than in acidosis rats (Figure 5b). In contrast, AQP2 band density in the low-density membrane fraction, which contains predominantly intracellular vesicles, was lower in control than in acidosis rats (Figure $5 \mathrm{c}$ ). These results suggested that the translocation of AQP2 between the plasma membrane and intracellular vesicles was impaired by metabolic acidosis.
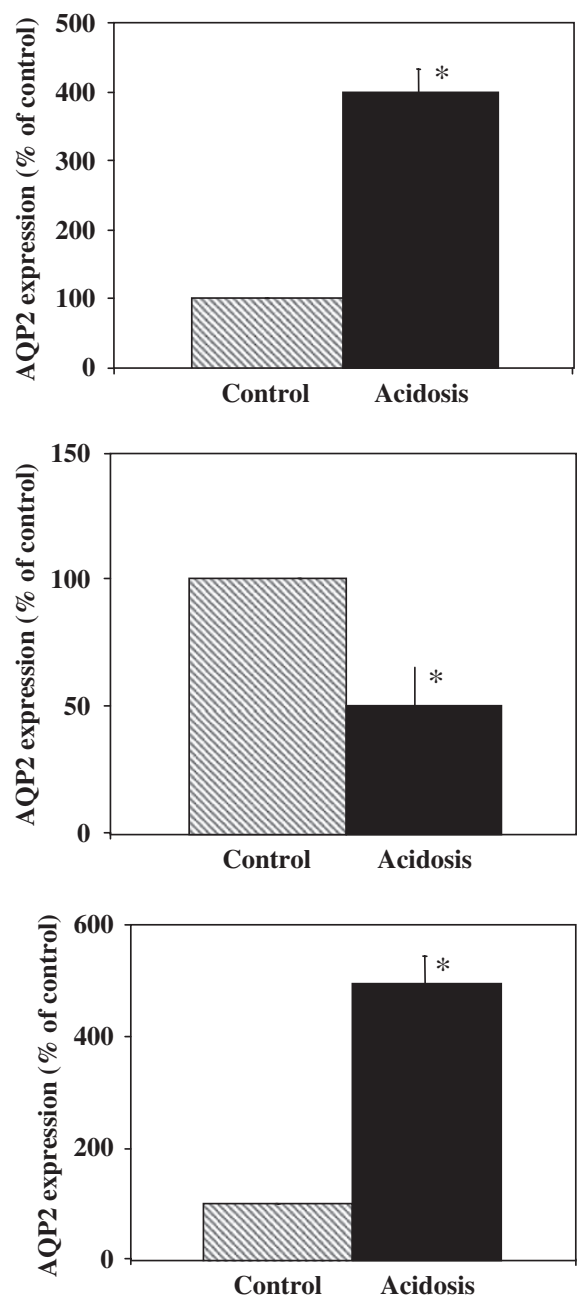

Figure 5 Differential centrifugation. The left panel shows a typical example of the western blot. The right graph shows a mean \pm s.e. of four experiments. There was a significant increase in AQP2 band density in whole-kidney homogenates from acidosis rats relative to control rats (a), in agreement with the results of immunoblot using microdissected OMCDs (Figure 3). In the high-density membrane fraction, which contains predominantly plasma membrane, AQP2 band density was higher in control than that in acidosis rats (b). In contrast, AQP2 band density in the low-density membrane fraction, which contains predominantly intracellular vesicles, was lower in control than that in acidosis rats (c). ${ }^{*} P<0.05$ vs. control. AQP2, aquaporin-2; OMCD, outer medullary collecting duct. 
Immunocytochemical localization of AQP2 in OMCD and inner medullary collecting duct (IMCD) from control, acidosis and acidosis plus dehydration rats

The kidney blocks from control, acidosis and acidosis plus dehydration rats were used for immunocytochemistry. Confocal laser scanning microscopy revealed that AQP2 was present mainly in the apical plasma membrane of the principal cell of OMCD and IMCD in control rats (Figures 6Aa and $\mathrm{Ba}$ ). In contrast, the diffuse localization of AQP2 in the cytoplasm of the principal cells was observed both in OMCD and in IMCD in metabolic acidosis (Figures 6Ab and $\mathrm{Bb}$ ). In metabolic acidosis with 2-days dehydration rats, AQP2 was present mainly in the apical plasma membrane of the principal cells as seen in control rats (Figures 6Ac and $\mathrm{Bc}$ ).

\section{DISCUSSION}

Our data show that urine osmolality and AQP2 protein in urine were decreased even with the increased AQP2 protein and mRNA expression in the collecting ducts by metabolic acidosis. Immunocytochemistry revealed that metabolic acidosis changed intracellular AQP2 localization from luminal membrane to the cytoplasm of principal cells. These observations suggested that trafficking of AQP2 between intracellular store and apical plasma membrane is affected by metabolic acidosis. Urinary excretion of AQP2 is not a marker of AQP2 expression in the kidney.
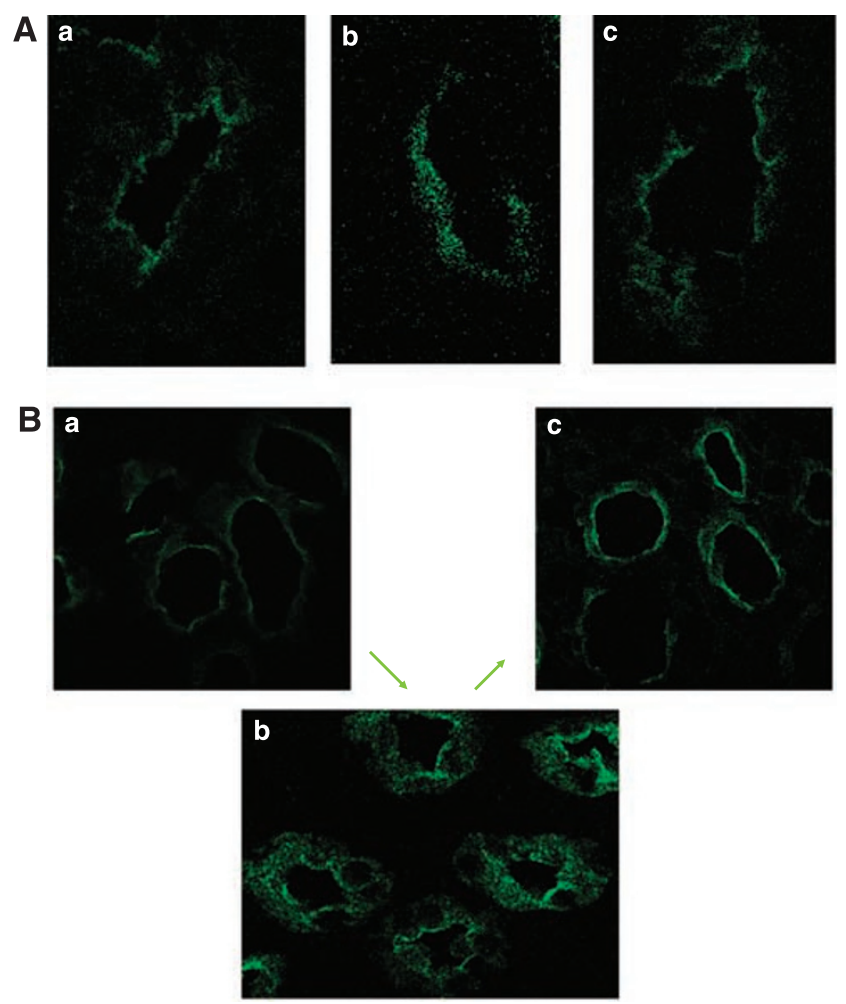

Figure 6 Immunocytochemical localization of aquaporin-2 (AQP2) in outer medullary collecting duct (OMCD) (a) and inner medullary collecting duct (IMCD) (b) from control, acidosis and acidosis plus dehydration rats. AQP2 was present mainly in the apical plasma membrane in the principal cell of OMCD and IMCD in control rats ( $\mathbf{A a}$ and $\mathbf{B a}$ ). In contrast, the diffuse presence of AQP2 in the cytoplasm of principal cells was observed in metabolic acidosis (Ab and $\mathbf{B b}$ ). Acidosis rats were dehydrated by removing tap water for 2 days. In metabolic acidosis with dehydration rats, AQP2 was present mainly in the apical plasma membrane of principal cells same as that in control rats ( $\mathbf{A} \mathbf{c}$ and $\mathbf{B C}$ ).
Metabolic acidosis develops with a reduction of the renal function and plays an important role in the progression of chronic renal failure. ${ }^{1}$ The drinking method of the $0.28 \mathrm{M} \mathrm{NH}_{4} \mathrm{Cl}$ solution had been used for the induction of metabolic acidosis for many years. However, the $0.28 \mathrm{M} \mathrm{NH}_{4} \mathrm{Cl}$ solution is hypertonic and will cause an increase in plasma osmolality and a subsequent stimulation of the plasma level of vasopressin. ${ }^{12,13}$ The drinking method of the $0.28 \mathrm{M}$ $\mathrm{NH}_{4} \mathrm{Cl}$ solution will also decrease the appetite and body weight of rats compared with that of control rats. Taken together, the drinking method of the $0.28 \mathrm{M} \mathrm{NH}_{4} \mathrm{Cl}$ solution induces metabolic acidosis with dehydration. This model is not good for the examination of AQP2, as vasopressin is known to stimulate AQP2 expression. In contrast, our model rat is not dehydrated. ${ }^{15}$ Plasma levels of vasopressin and body weight were not different from that of control rats. Ages and strain of rats may play some role in the plasma levels of arginine vasopressin (AVP). We used young rats as we microdissected OMCD. Frische et al. ${ }^{24}$ reported the same plasma osmolality in acidotic and control rats using almost similar protocols as ours for making acidotic rats. In our acidosis rats, urine volume increased twofold compared with that in control rats, suggesting that the addition of $\mathrm{NH}_{4} \mathrm{Cl}$ may cause osmotic diuresis in our model. The decrease in the urinary excretion of AQP2 by metabolic acidosis is larger than the difference in urine osmolality. The defect in trafficking of AQP2 is suggested.

AQP2 is a vasopressin-sensitive water channel and is present in the principal cells of the collecting ducts. ${ }^{5,6}$ The proportional increase in principal cells in the deeper collecting ducts related to the increase in AQP2 in the deeper collecting ducts and to the osmotic gradient of medullary interstitium. The mechanisms of increased expression of AQP2 in the collecting ducts by acidosis are not clear. As plasma AVP concentration was not different between acidosis and control rats, plasma levels of AVP play no role in the increased AQP2 expression in the collecting ducts by acidosis. We have reported that V1a receptordeficient mice showed decreased renin-angiotensin-aldosterone (RAA) system and V2R-AQP2 system. ${ }^{25} \mathrm{~V} 1 \mathrm{aR}$ in the macula densa cells regulates both the RAA system and the V2R-AQP2 system. Increased $\mathrm{V} 1 \mathrm{aR}$ in acidosis may stimulate the RAA system and the V2R-APQ2 system, resulting in the increase in AQP2 expression in the collecting ducts in this study. We have reported that metabolic acidosis decreased the expression of V2 receptor mRNA in the collecting ducts of rats. ${ }^{11}$ Therefore, it is possible that increased V1aR may directly stimulate the AQP2 expression in metabolic acidosis.

Immunocytochemistry revealed the diffuse localization of AQP2 in the cytoplasm of principal cells by metabolic acidosis, which is compatible with the decreased urinary expression of AQP2. Control and metabolic acidosis together with dehydration, showed the subapical localization of AQP2 mainly in the collecting ducts (Figure 6). Bouley et al. ${ }^{26}$ clearly showed the vasopressin-induced translocation of AQP2 to the apical plasma membrane in the collecting duct principal cells. As our control rats showed high urine osmolality $(1670 \mathrm{mOsm}$ per $\mathrm{kg} \mathrm{H}_{2} \mathrm{O}$ ), AQP2 was thought to be present mainly in the apical plasma membrane even in the control condition. However, urine osmolality in normal rats was high compared with that in humans. ${ }^{15}$ Urine osmolality in acidosis rats was lower than in control, because of the decreased expression of AQP2 in the apical plasma membrane. Differential centrifugation confirmed the results. AQP2 is stored in the intracellular vesicle, and trafficking to the apical plasma membrane is stimulated by vasopressin.9,10 Metabolic acidosis is thought to decrease intracellular trafficking of AQP2. The induction of dehydration in the acidosis rats stimulated the translocation of AQP2 from intracellular vesicles to the apical plasma membrane, suggesting that the defect of intracellular trafficking of AQP2 by 
metabolic acidosis is not the decrease in vasopressin action in the collecting ducts. Precise mechanisms of the decrease in intracellular trafficking by metabolic acidosis are not known. As metabolic acidosis induced intracellular acidosis, intracellular acidosis may inhibit intracellular trafficking of AQP2. Hypokalemia is also known to induce intracellular acidosis. ${ }^{27,28}$ Hypokalemia also decreased AQP2 expression to $27 \%$ of controls in the inner medulla. ${ }^{29}$ As hypokalemia causes polyuria and low urine osmolality, reduced urinary excretion of AQP2 is speculated. It would be interesting to examine the intracellular localization of AQP2 in hypokalemia. It is speculated that intracellular acidosis may play a key role in the downregulation of intracellular trafficking of AQP2.

The mechanisms of AQP2 trafficking are classified into two groups: cAMP (cyclic adenosine monophosphate)-dependent and -independent pathways. ${ }^{9,10}$ As the plasma level of vasopressin in our acidosis rats is not different from that in control, participation of cAMPdependent pathways would be less in the acidosis-mediated inhibition of AQP2 in the plasma membrane. Internalization of AQP2 is a clathrin-mediated mechanism. Chou et al. ${ }^{30}$ revealed that AQP2 trafficking is calmodulin-dependent and $\mathrm{Ca}^{++}$release from ryanodine-sensitive stores plays an essential role. Acute hypertonicity induced cell surface expression of AQP2 through the activation of MAP kinase. ${ }^{31}$ AQP2 trafficking is regulated by the phosphorylation of serine 256 residues in its cytoplasmic domain. ${ }^{32}$ Intracellular acidosis may affect these pathways, resulting in the inhibition of accumulation of AQP2 in the apical plasma membrane. Reduced trafficking of AQP2 by metabolic acidosis is a good model for investigating the mechanisms of AQP2 trafficking.

In summary, metabolic acidosis caused an increased expression of AQP2 in the collecting ducts with diffuse intracellular localization, suggesting the reduction of intracellular trafficking of AQP2. Osmotic diuresis may partly cause the decrease in urinary excretion of AQP2.

1 Hayslett JP. Functional adaptation to reduction in renal mass. Physiol Rev 1979; 59: 137-164.

2 Sands JM, Nonoguchi $\mathrm{H}$, Knepper MA. Vasopressin effects on urea and $\mathrm{H}_{2} \mathrm{O}$ transport in inner medullary collecting duct subsegments. Am J Physiol 1987; 253: F823-F832.

3 Inoue T, Nonoguchi H, Tomita K. Physiological effects of vasopressin and atrial natriuretic peptide in the collecting duct. Cardiovasc Res 2001; 51: 470-480.

4 Bankir L. Antidiuretic action of vasopressin: quantitative aspects and interaction between V1a and V2 receptor-mediated effects. Cardiovasc Res 2001; 51: 372-390.

5 Fushimi K, Uchida S, Hara Y, Hirata Y, Marumo F, Sasaki S. Cloning and expression of apical membrane water channel of rat kidney collecting tubule. Nature 1993; 361: 549-552.

6 Nielsen S, Frokiaer J, Marples D, Kwon TH, Agre P, Knepper MA. Aquaporins in the kidney: from molecules to medicine. Physiol Rev 2002; 82: 205-244.

7 Boone M, Deen PM. Physiology and pathophysiology of the vasopressin-regulated renal water reabsorption. Pflugers Arch 2008; 456: 1005-1024.

8 Rai T, Sekine K, Kanno K, Hata K, Miura M, Mizushima A, Marumo F, Sasaki S. Urinary excretion of aquaporin-2 water channel protein in human and rat. J Am Soc Nephrol 1997; 8: 1357-1362.

9 Knepper MA, Inoue T. Regulation of aquaporin-2 water channel trafficking by vasopressin. Curr Opin Cell Biol 1997; 9: 560-564.
10 Brown D. The ins and outs of aquaporin-2 trafficking. Am J Physiol Renal Physiol 2003; 284: F893-F901.

11 Tashima Y, Kohda Y, Nonoguchi H, Ikebe M, Machida K, Star RA, Tomita K. Intranephron localization and regulation of the $\mathrm{V} 1 \mathrm{a}$ vasopressin receptor during chronic metabolic acidosis and dehydration in rats. Pflugers Arch 2001; 442: 652-661.

12 Amlal H, Sheriff S, Soleimani M. Upregulation of collecting duct aquaporin-2 by metabolic acidosis: role of vasopressin. Am J Physiol Cell Physiol 2004; 286 : C1019-C1030.

13 Nonoguchi H, Inoue T, Mori T, Nakayama Y, Kohda Y, Tomita K. Regulation of aquaporin-2 by metabolic acidosis. Am J Physiol Cell Physiol 2004; 287: C824.

14 Promeneur D, Kwon TH, Yasui M, Kim GH, Frøkiaer J, Knepper MA, Agre P, Nielsen S. Regulation of AQP6 mRNA and protein expression in rats in response to altered acidbase or water balance. Am J Physiol Renal Physiol 2000; 279: F1014-F1026.

15 Imanishi K, Nonoguchi H, Nakayama Y, Machida K, Ikebe M, Tomita K. Type 1 A angiotensin II receptor is regulated differently in proximal and distal nephron segments. Hypertens Res 2003; 26: 405-411.

16 Higuchi R. Recombinant PCR. In Innis MA, Gelfand DH, Sninsky JJ, White TJ (eds). PCR Protocols. Academic Press: San Diego, CA, 1990, pp 177-183.

17 Nakayama Y, Nonoguchi H, Kiyama S, Ikebe M, Tashima Y, Shimada K, Tanzawa K, Tomita K. Intranephron distribution and regulation of endothelin-converting enzyme-1 in cyclosporin A-induced acute renal failure in rats. J Am Soc Nephrol 1999; 10: 562-571.

18 Valenti G, Laera A, Pace G, Aceto G, Lospalluti ML, Penza R, Selvaggi FP, Chiozza ML, Svelto M. Urinary aquaporin 2 and calciuria correlate with the severity of enuresis in children. J Am Soc Nephrol 2000; 11: 1873-1881.

19 Wen H, Frokiaer J, Kwon TH, Nielsen S. Urinary excretion of aquaporin-2 in rat is mediated by a vasopressin-dependent apical pathway. J Am Soc Nephrol 1999; 10: 1416-1429.

20 Nonoguchi H, Owada A, Kobayashi N, Takayama M, Terada Y, Koike J, Ujiie K, Marumo F, Sakai T, Tomita K. Immunohistochemical localization of V2 vasopressin receptor along the nephron and functional role of luminal V2 receptor in terminal inner medullary collecting ducts. J Clin Invest 1995; 96: 1768-1778.

21 Inoue T, Terris J, Ecelbarger CA, Chou CL, Nielsen S, Knepper MA. Vasopressin regulates apical targeting of aquaporin-2 but not of UT1 urea transporter in renal collecting duct. Am J Physiol 1999; 276: F559-F566.

22 Ecelbarger CA, Terris J, Frindt G, Echevarria M, Marples D, Nielsen S, Knepper MA. Aquaporin-3 water channel localization and regulation in rat kidney. Am J Physiol 1995; 269: F663-F672.

23 Marples D, Knepper MA, Christensen EI, Nielsen S. Redistribution of aquaporin-2 water channels induced by vasopressin in rat kidney inner medullary collecting duct. Am J Physiol 1995; 269: C655-C664.

24 Frische S, Kwon TH, Frøkiaer J, Madsen KM, Nielsen S. Regulated expression of pendrin in rat kidney in response to chronic $\mathrm{NH} 4 \mathrm{Cl}$ or $\mathrm{NaHCO} 3$ loading. Am J Physiol Renal Physiol 2003; 284: F584-F593.

25 Aoyagi T, Izumi Y, Hiroyama M, Matsuzaki T, Yasuoka Y, Sanbe A, Miyazaki H, Fujiwara Y, Nakayama Y, Kohda Y, Yamauchi J, Inoue T, Kawahara K, Saito H, Tomita K, Nonoguchi H, Tanoue A. Vasopressin regulates the renin-angiotensin-aldosterone system via V1a receptors in macula densa cells. Am J Physiol Renal Physiol 2008; 295: F100-F107.

26 Bouley R, Breton S, Sun T, McLaughlin M, Nsumu NN, Lin HY, Ausiello DA, Brown D. Nitric oxide and atrial natriuretic factor stimulate cGMP-dependent membrane insertion of aquaporin 2 in renal epithelial cells. J Clin Invest 2000; 106: 1115-1126.

27 Adler S, Fraley DS. Potassium and intracellular pH. Kidney Int 1977; 11: 433-442.

28 Amemiya M, Tabei K, Kusano E, Asano Y, Alpern RJ. Incubation of OKP cells in low- $\mathrm{K}^{+}$ media increases NHE3 activity after early decrease in intracellular pH. Am J Physiol 1999; 276: C711-C716.

29 Marples D, Frokiaer J, Dorup J, Knepper MA, Nielsen S. Hypokalemia-induced downregulation of aquaporin-2 water channel expression in rat kidney medulla and cortex. J Clin Invest 1996; 97: 1960-1968.

30 Chou CL, Yip KP, Michea L, Kador K, Ferraris JD, Wade JB, Knepper MA. Regulation of aquaporin2 trafficking by vasopressin in the renal collecting duct. Roles of ryanodinesensitive $\mathrm{Ca}^{++}$stores and calmodulin. J Biol Chem 2000; 275: 36839-36846.

31 Hasler U, Nunes P, Bouley R, Lu HA, Matsuzaki T, Brown D. Acute hypertonicity alters aquaporin-2 trafficking and induces a MAP kinase-dependent accumulation at the plasma membrane of renal epithelial cells. J Biol Chem 2008; 283: 26643-26661.

32 Brown D, Hasler U, Nunes P, Bouley R, Lu HA. Phosphorylation events and the modulation of aquaporin 2 cell surface expression. Curr Opin Nephrol Hypertens 2008; 17: 491-498. 